\title{
Childhood Asthma - The Effect of Asthma Specialist Intervention on Asthma Control: A Retrospective Review
}

\author{
Yossi Rosman (D) ${ }^{1,2}$ \\ Linoy Gabay ${ }^{3}$ \\ Tami Landau $\mathbb{D}^{3}$ \\ Ronit Confino-Cohen ${ }^{1,2}$
}

'Allergy and Clinical Immunology Unit, Meir Medical Center, Kfar Saba, Israel; ${ }^{2}$ Sackler Faculty of Medicine, Tel-Aviv University, Tel Aviv, Israel; ${ }^{3}$ Maccabitech Institute for Research and Innovation, Maccabi Healthcare Services, Tel Aviv, Israel
Correspondence: Yossi Rosman Allergy and Clinical Immunology Unit, Meir Medical Center, Tshernichovsky Street 59, Kfar Saba, 4428I64, Israel $\mathrm{Tel} / \mathrm{Fax}+$ I 97237372717

Email rosmanyossi@gmail.com
Background: Childhood asthma is the most common chronic disease throughout the western world. Improving asthma control is a leading health management goal.

Purpose: To evaluate the effect of an intervention by a visit to an asthma specialist on asthma control in children.

Materials and Methods: This retrospective study was conducted using the electronic database of Maccabi Health Services. All members ages 5-16 with an asthma diagnosis during 2000-2016, and at least one visit to a specialist were included. Asthma outcomes during the 2 years before and after the visit to the asthma specialist were compared.

Results: A total of 37,066 children were diagnosed with asthma. Among them, 13,533 (36.5\%) had at least one visit to an asthma specialist and were included. Children with asthma visited their primary care physician more often in the period before the specialist visit $(4.4 \pm 4.4$ vs $3.16 \pm 3.9$ visits, respectively; $\mathrm{p}<0.01)$. After visiting a specialist, average number of visits to emergency departments $(0.52 \pm 1.3$ vs $0.45 \pm 1)$, all cause hospitalizations $(0.13 \pm 0.45$ vs 0.08 $\pm 0.4)$ and hospitalizations due to asthma exacerbations $(0.08 \pm 0.345$ vs $0.05 \pm 0.3)$ decreased ( $p<0.01$ for all comparisons). Prescription of short-acting beta agonists decreased $(2.85 \pm 3.6$ vs $2.2 \pm 3.7, \mathrm{p}<0.01)$ and inhaled steroid prescriptions increased $(1.9 \pm 2.9$ vs $2.7 \pm 3.7, \mathrm{p}<0.01)$, respectively, after the intervention. A substantial reduction in the prescription of corticosteroids $(0.81 \pm 1.9$ vs $0.43 \pm 1.4, \mathrm{p}<0.01)$ after specialist visit was also noted.

Conclusion: We found significant positive outcomes after a single consultation with an asthma specialist. Referring pediatric asthma patients to an asthma specialist should be one of the goals of an asthma management plan.

Keywords: asthma, children, specialist, pediatrics

\section{Introduction}

Throughout the western world, childhood asthma is the most common chronic disease affecting more than 5 million children in the United States alone. ${ }^{1,2}$ Asthma is mostly incurable, and the aim of treatment is to minimize exacerbations, improve quality of life and to prevent lung function deterioration. In children, asthma exacerbations can lead to numerous visits to pediatricians, emergency departments and hospital admissions. Uncontrolled asthma leads to frequent use of asthma relievers and systemic corticosteroids, consequently increase patients' risks for long-term side-effects. In the western world, uncontrolled asthma in children is a substantial cause of absence from school and missed workdays of their caregivers; leading to considerable direct and indirect costs. ${ }^{3-5}$ 
Improving asthma control in general and particularly in children, is a leading health management goal. To achieve this, various interventions have been suggested. These measures include parental education ${ }^{6}$ home monitoring of disease control using an objective assessment measure, such as peak expiratory flow measurements, and easy access to health care providers. ${ }^{7}$

Specialist referral is recommended by the Asthma Education Program Expert Panel as well as by the Global Strategy for Asthma Management and Prevention for patients older than five years. ${ }^{8}$ Some evidence also supports intervention for adults by asthma specialists. This is expressed by a decline in hospitalization rates and better level of asthma control. ${ }^{8,9}$ Although recommended for children, the effect of asthma specialists' intervention on asthma control in the pediatric population is much less explored. ${ }^{9-11}$

The current study evaluated the effect of asthma specialists' intervention on asthma control, in a large group of Israeli children.

\section{Materials and Methods Study Design and Data Source}

This retrospective, population-based cohort study was conducted using the electronic medical records of Maccabi Health Services (MHS). MHS is both an insurer and provider and is the second largest of Israel's four Health Maintenance Organizations, covering about 2.4 million patients $(26.5 \%$ of the total population). MHS provides community-based medical services from primary care physicians (PCP) and pediatricians, as well as other specialties, including asthma specialists (allergists and pulmonologists). In 1999, MHS created a centralized electronic database that contains electronic records from primary care, specialty clinics, hospitals, pharmacies and laboratories. In addition, it contains demographic and socio-economic information derived from Israel's Central Bureau of Statistics and the Israel National Insurance (Social Security). The data are comprehensive, as members receive most of their care within MHS.

Use of the electronic medical record (EMR) data in this study was approved by the MHS Institutional Review Board.

\section{Study Cohort}

All MHS members ages 5 to 16 who had an asthma diagnosis during the study period (2000-2016) and at least one visit to an asthma specialist were included in the study. We limited the sample to children older than 5 years of age to minimize the possibility of disease misclassification, possibly confusing childhood transient or infectious wheezing for asthma.

Demographic data, including age, sex, BMI, geographic district, and socioeconomic status were included in the analysis. Laboratory results, including eosinophil counts were collected. High blood eosinophils were defined as above $600 \mathrm{micl} / \mathrm{K}$.

Asthma outcomes 2 years before the visit to the asthma specialist and 2 years afterwards were compared. These included prescriptions for systemic steroids, inhaled steroids (as single or combined inhalers) and short-acting beta agonists. Healthcare visits (PCP and emergency centers) and hospital admissions were also compared.

Patients who did not have 4 years of follow-up data were excluded from the study.

\section{Statistical Analysis}

Asthma outcomes were compared before and after the visit to the asthma specialist using nonparametric McNemar or Wilcoxon tests for categorical variables, dependent on the number of categories compared, and paired $T$-test for continuous variables.

We used a logistic multivariate regression model to assess the influence of asthma specialist visits and asthma exacerbation, controlling for demographic and clinical variables. P-values less than 0.05 were considered to indicate statistically significant differences.

All analyses were performed using IBM SPSS, version 25.0 (IBM Corp., Armonk, NY) and R statistical programming language (version 3.5.1).

\section{Results}

During the 2000-2016 study period, a total of 37,066 children ages 5-16 were diagnosed with asthma. Among them, $13,533(36.5 \%)$ had at least one visit to an asthma specialist and were included in the study. Demographic data are presented in Table 1.The cohort included 8558 males (63\%). The average age was $10.14 \pm 2.84$ years. None of the children had a chronic disease, other than asthma. However, 586 (4\%) were defined as obese with BMI $>35$. Forty-two percent of the children lived in central Israel, whereas $14 \%$, $26 \%$ and $18 \%$ lived in the southern, inner valley and northern parts of the country, respectively. This is comparable to the distribution of the general pediatric population in Israel. Most patients $(6989,51.6 \%$ ) were from families of 
Table I Demographics of the Study Cohort $(N=13,533)$

\begin{tabular}{|c|c|c|}
\hline \multicolumn{2}{|l|}{ Sex (male)- N (\%) } & 8558 (63\%) \\
\hline \multicolumn{2}{|l|}{ Age, years Mean $\pm S D$} & $10.14 \pm 2.8$ \\
\hline \multirow[t]{3}{*}{ Socioeconomic status, N (\%) } & Low & 1879 (13.9\%) \\
\hline & Intermediate & 6989 (5I.6\%) \\
\hline & High & 4665 (34.5\%) \\
\hline \multicolumn{2}{|l|}{ BMI >35- N (\%) } & $586(4 \%)$ \\
\hline \multirow[t]{3}{*}{ Eosinophils - N (\%) } & $<0.6$ & $6910(51.1 \%)$ \\
\hline & $\geq 0.6$ & $3458(25.5 \%)$ \\
\hline & Missing & $3165(23.4 \%)$ \\
\hline
\end{tabular}

intermediate socioeconomic status, whereas 4665 (34.5\%) were from families with a high socioeconomic status and the rest had low socioeconomic status. This is also comparable to the general socioeconomic distribution in Israel.

\section{Primary Care Physician, Emergency Department Visits and Hospitalizations}

We compared clinical outcomes 2 years before and 2 years after a visit to an asthma specialist (Table 2, Figure 1). Children with asthma visited their PCP significantly more in the period before the specialist visit as compared to the two years after $(4.4 \pm 4.4$ visits vs $3.16 \pm 3.9$ visits, respectively; $\mathrm{p}<0.01$ ). A subgroup of $12.2 \%$ of the children (1657) did not visit a PCP before the specialist intervention vs $3295(24.3 \%)$ after the visit $(\mathrm{p}<0.01)$. Likewise, 5008 (37\%) had multiple visits ( $>5)$ to their PCP before vs $3.284(24.3 \%)$ after the intervention $(p<0.01)$.

After visiting a specialist, the average number of visits to immediate care centers and emergency departments decreased significantly $(0.52 \pm 1.3$ vs $0.45 \pm 1$ visits, respectively; $\mathrm{p}<0.01)$. Before visiting the specialist, 3710

Table 2 Asthma Clinical Outcomes Before and After Intervention

\begin{tabular}{|c|c|c|c|c|}
\hline Outcome & & Before $N=13,533$ & After $\mathrm{N}=13,533$ & P-value \\
\hline \multirow[t]{7}{*}{ No. of primary physician visits } & 0 & 1657 (12.2\%) & $3295(24.3 \%)$ & $<0.01$ \\
\hline & I & 1966 (14.5\%) & 2490 (18.4\%) & \\
\hline & 2 & 1847 (13.6\%) & 1977 (|4.6\%) & \\
\hline & 3 & 1720 (12.7\%) & 1406 (10.4\%) & \\
\hline & 4 & 1335 (9.9\%) & $1081(8.0 \%)$ & \\
\hline & $\geq 5$ & 5008 (37.0\%) & 3284 (24.3\%) & \\
\hline & Average & $4.4 \pm 4.4$ & $3.1 \pm 3.9$ & $<0.01$ \\
\hline \multirow[t]{2}{*}{ No. of Emergency services visits } & $\geq 1$ & $3710(27.4 \%)$ & 3491 (25.8\%) & $<0.01$ \\
\hline & Average & $0.5 \pm 1.3$ & $0.4 \pm 1$ & $<0.01$ \\
\hline \multirow[t]{2}{*}{ All-cause hospitalization } & $\geq 1$ & 1377 (I0.2\%) & $873(6.5 \%)$ & $<0.01$ \\
\hline & Average & $0.13 \pm 0.45$ & $0.08 \pm 0.4$ & $<0.01$ \\
\hline \multirow[t]{2}{*}{ Hospitalization due to asthma exacerbations } & $\geq 1$ & $799(5.9 \%)$ & $512(3.8 \%)$ & $<0.01$ \\
\hline & Average & $0.08 \pm 0.35$ & $0.05 \pm 0.3$ & $<0.01$ \\
\hline \multirow[t]{5}{*}{ Rescue medication use (no. of short-acting beta agonist prescriptions) } & 0 & 2939 (21.7\%) & $4752(35.1 \%)$ & $<0.01$ \\
\hline & I & $2839(21.0 \%)$ & $2867(21.2 \%)$ & \\
\hline & 2 & $2284(16.9 \%)$ & $194 \mid(14.3 \%)$ & \\
\hline & $\geq 3$ & $547 \mathrm{I}(40.4 \%)$ & $3973(29.4 \%)$ & \\
\hline & Average & $2.85 \pm 3.6$ & $2.2 \pm 3.3$ & $<0.01$ \\
\hline \multirow[t]{5}{*}{ Chronic medication use (no. of prescriptions) } & 0 & $4373(32.3 \%)$ & $4300(31.8 \%)$ & $<0.01$ \\
\hline & I & $3482(25.7 \%)$ & $2634(19.5 \%)$ & \\
\hline & 2 & $2153(15.9 \%)$ & 1828 (I3.5\%) & \\
\hline & $\geq 3$ & $3525(26.0 \%)$ & 4771 (35.3\%) & \\
\hline & Average & $1.9 \pm 2.85$ & $2.7 \pm 1.4$ & $<0.01$ \\
\hline \multirow[t]{2}{*}{ Systemic steroid use (no. of prescriptions) } & $\geq 1$ & $5619(41.5 \%)$ & $3458(25.6 \%)$ & $<0.01$ \\
\hline & Average & $0.8 \pm 1.9$ & $0.4 \pm 1.4$ & $<0.01$ \\
\hline
\end{tabular}


Asthma control parameters - before and after intervention

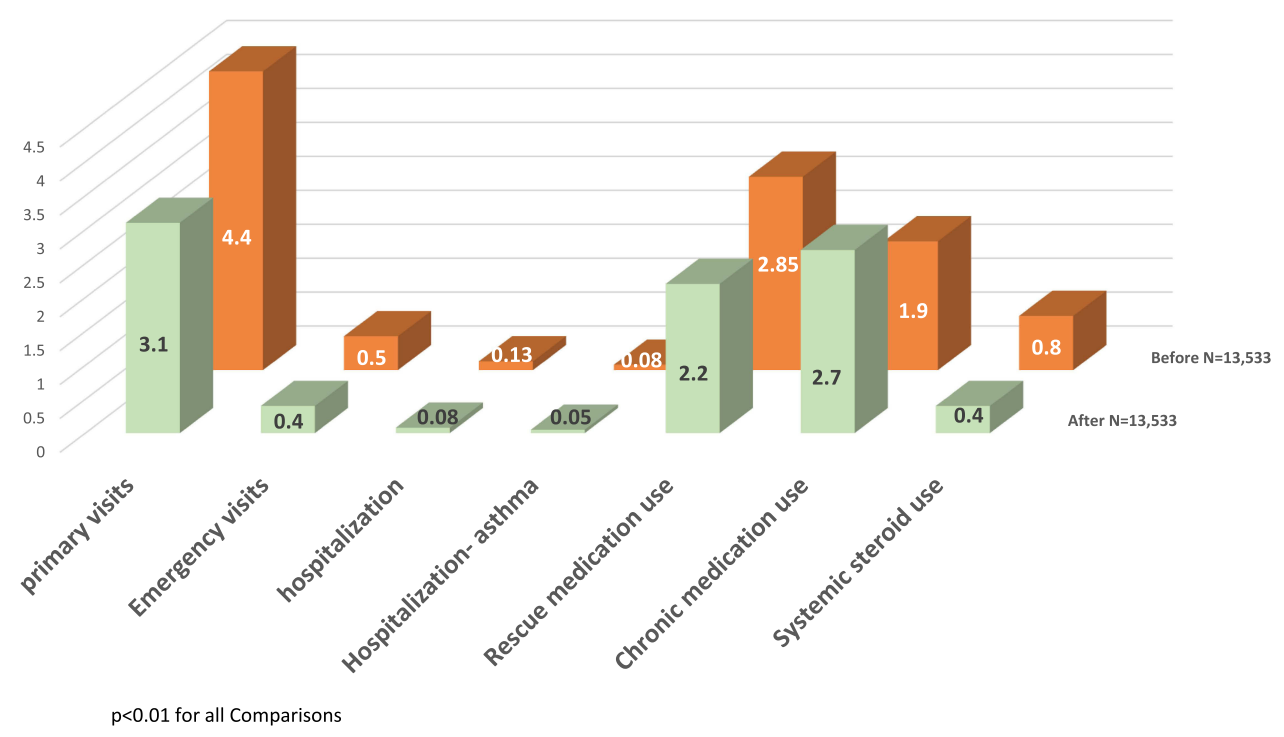

Figure I Asthma control parameters -before and after specialist intervention.

patients (27.4\%) had at least one ER visit vs 3491 (25.8\%) after, $\mathrm{p}<0.01$. Moreover, average all-cause hospitalizations $(0.13 \pm 0.45$ vs $0.08 \pm 0.4)$ and hospitalizations due to asthma exacerbation $(0.08 \pm 0.345$ vs $0.05 \pm 0.3)$ were decreased significantly after the specialist intervention ( $<<0.01$ for all comparisons). A total of 1377 (10.2\%) patients had at least one hospitalization before specialist intervention, vs $873(6.5 \%)$ after $(\mathrm{p}<0.01)$.

\section{Rescue Medication and Steroid Treatment}

Along with fewer visits to PCPs and emergency services, we found an improvement in the treatment regimen after the specialist intervention. This was evident by a significant reduction prescription of short-acting beta agonists (rescue medication) (2.85 \pm 3.6 vs $2.2 \pm 3.7$, $\mathrm{p}<0.01)$ along with an increase in inhaled steroid prescriptions $(1.9 \pm 2.9$ vs $2.7 \pm 3.7, \mathrm{p}<0.01)$. Only 2939 (21.7\%) patients did not use beta agonists before intervention vs $4752(35.1 \%)$ after $(\mathrm{p}<0.01)$. Similarly, fewer patients used beta agonists regularly ( $\geq 3$ prescriptions) after the specialist intervention (5471 (40.4\%) vs 3973 (29.4\%); $\mathrm{p}<0.01)$. Moreover, we found a substantial decrease in the number of children prescribed oral corticosteroids (5619 $(41.5 \%)$ vs $3458(25.6 \%), \mathrm{p}<0.01)$ and in the average prescription of corticosteroids $(0.81 \pm 1.9$ vs $0.43 \pm 1.4$, $\mathrm{p}<0.01)$ after the specialist visit.

\section{Multivariate Logistic Regression}

A multivariate logistic regression was calculated for all outcomes (Table 3). Previous hospital admissions $(\mathrm{OR}=2.93 ; 95 \% \mathrm{CI}(2.48-3.47), \mathrm{p}<0.001)$ and low socioeconomic group ( $\mathrm{OR}=0.9 ; 95 \% \mathrm{CI}(0.87-0.94), \mathrm{p}<0.001)$ were found to be independent risk-factors for future hospital admissions. Previous ER visits ( $\mathrm{OR}=1.96 ; 95 \% \mathrm{CI}$ $(1.79-2.14), \mathrm{p}<0.001)$ and male sex $(\mathrm{OR}=1.3 ; 95 \% \mathrm{CI}$ (1.19-1.42), $\mathrm{p}<0.001$ ) were found to be independent riskfactors for future ER visits. Use of rescue medication $(\mathrm{OR}=3.5 ; 95 \%$ CI $(3.17-3.87), \mathrm{p}<0.001)$, younger age $(\mathrm{OR}=0.93 ; 95 \%$ CI $(0.91-0.94), \mathrm{p}<0.001)$ and high blood eosinophil levels (OR=1.67; 95\% CI (1.49-1.88), $\mathrm{p}<0.001)$ were found to be independent risk-factors for future need for rescue medications. Use of systemic steroids $(\mathrm{OR}=3.89 ; 95 \% \mathrm{CI}(3.54-4.28), \mathrm{p}<0.001)$, younger age ( $\mathrm{OR}=0.92 ; 95 \% \mathrm{CI}(0.91-0.94), \mathrm{p}<0.001)$, high blood eosinophil levels $(\mathrm{OR}=1.11 ; 95 \% \mathrm{CI}(1-1.23), \mathrm{p}=0.05)$ and male sex $(\mathrm{OR}=1.1 ; 95 \% \mathrm{CI}(1-1.22), \mathrm{p}<0.05)$ were independent risk-factors for future need for systemic steroids.

\section{Discussion}

Pediatric asthma affects up to $10 \%$ of children. It has considerable effects on quality of life, demands on health resources and is an economic burden. ${ }^{12}$ All of these are substantially improved when asthma is well-controlled. However, according to data from the US, asthma control 


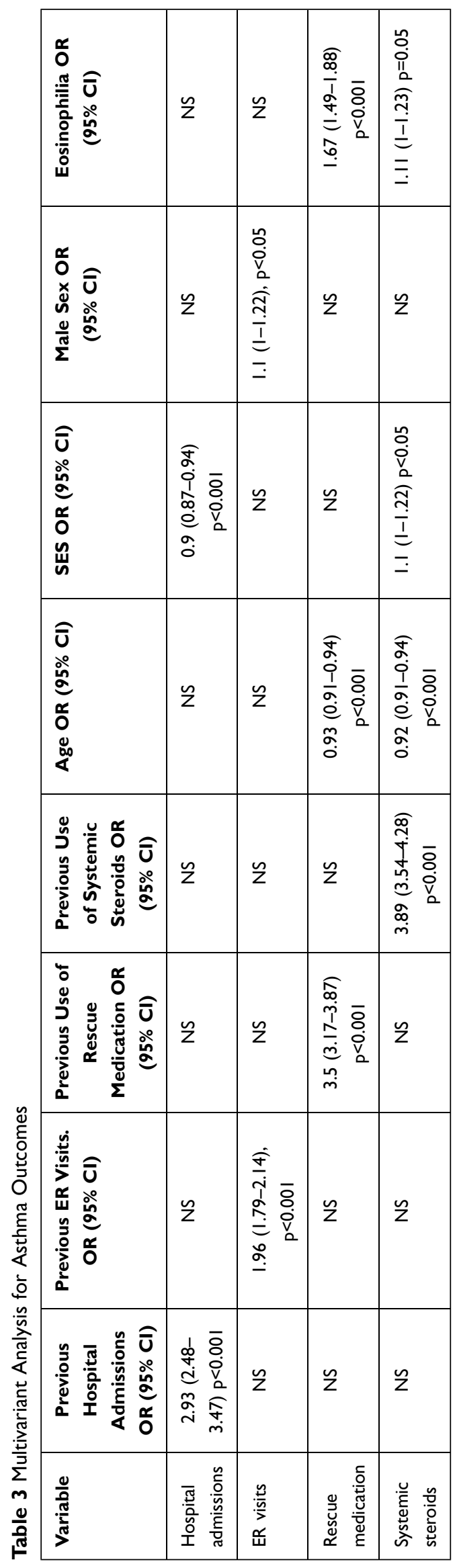

is insufficient in almost half of diagnosed children ${ }^{13}$ Lack of control is presented as excessive use of rescue medications, recurrent visits to PCPs and ERs, as well as use of systemic corticosteroids and hospitalizations. Many efforts have been invested to improve asthma control: education of caregivers using community support and artificial intelligence ${ }^{14}$ home peak-flow measurements, as well as instructions on use of control medications; ${ }^{7}$ all with only modest effects.

The current study evaluated the effect of a visit to an asthma specialist on asthma control. We found, significant positive effects of a specialist consultation, influencing all elements of disease control, in a large heterogeneous group of asthmatic children.

Asthma exacerbation in children usually needs intervention. The action taken is largely dependent on environmental circumstances, such as the presence of an adult who can offer help, readily available rescue medication, availability of a PCP and accessibility to emergency medicine. In the Israeli healthcare system, all these are easily reachable. Accordingly, in our cohort, most of the children with asthma (78\%) used rescue medications and visited their PCP significantly more in the period before the visit to a specialist. After the visit, a significant reduction in the prescription of short-acting beta agonists was noted and visits to PCPs decreased significantly. More than one-third of the cohort had visited their PCP more than 5 times a year due to asthma exacerbations. After the specialist intervention, these "frequent visitors" comprised less than $25 \%$ of the cohort. Along with this shift, after visiting a specialist, the average number of visits to immediate care centers and emergency departments decreased, as well. These changes, which are speculated to be related to the meeting with the asthma expert, can be explained in a few ways. Accurate diagnosis of the disease stage and prescription of controller medications, as well as education regarding when and how to use rescue medications, which is a very important step in asthma management, were provided. Indeed, after the specialist intervention, a significant increase in prescriptions of control medications, mainly inhaled corticosteroids, was noted. The complementary effect of better control was expressed by a substantial decrease in the number of children who were prescribed oral corticosteroids and with a significant average reduction in the number of corticosteroid prescriptions after the specialist visit. 
Prescribing the correct control medication, along with education in its mode of use are among the most important means of asthma control. A recent survey of 1412 PCPs and 233 asthma specialists showed that adherence to asthma guidelines was higher among patients of specialists than of PCPs. ${ }^{15}$ These findings are also supported by the results of a survey administered to parents of pediatric patients seen in the emergency department for asthma. Among the 150 children, $75 \%$ had not met with an asthma specialist, suggesting sub-optimal chronic treatment. ${ }^{9}$

When emergency department treatment is insufficient, children with uncontrolled asthma might be hospitalized. In the present cohort, the average number of all-cause hospitalizations and hospitalizations due to asthma exacerbation decreased significantly after specialist intervention. Whether this reduction reflects a direct effect of the consultation with an expert has yet to be proven. Nonetheless, these data are supported by a retrospective, cross-sectional study from Canada that demonstrated a strong connection between the lack of asthma specialists and hospital admissions of children with asthma. ${ }^{10}$

Childhood asthma is a heterogeneous condition with wide variability among patients. ${ }^{16}$ It is reasonable to assume that not all patients who meet with a specialist will benefit directly from a single encounter. This is due to the limited effect of a single meeting, the need for more continuous support, or more severe disease, among other reasons.

Accordingly, multivariate analysis showed that hospital admissions and low socioeconomic group were independent risk-factors for future hospital admissions. In addition, previous ER visits were found to be independent risk-factors for future ER visits. These patients seem to be at higher risk for poorer outcomes, possibly suffering from asthma that is more severe or challenging to control. These patients would probably benefit from closer follow-up.

Achieving asthma control is a complicated mission. All means should be assembled-from patient and caregiver education to identifying exacerbating factors, such as allergens and smoking. A simplified treatment action plan and using an inhaler during school hours might help, as well.

The data presented in this study focus on the effect of an encounter with an asthma expert. This visit may accurately identify the diagnosis and its severity, by employing focused anamnesis, and skin and lung function tests; consequently, improving the treatment regimen, as well as the perspectives of patients and caregivers. We have demonstrated that this type of intervention significantly reduces all aspects of asthma exacerbation and substantially improves asthma control.

This study had several limitations inherent to its retrospective cohort design. We were unable to diagnose asthma according to guidelines, but relied on diagnoses in the EMR. However, since every child in the study population had visited an asthma specialist and most received asthmadirected treatments, this indicates that the study population had asthma. Second, as we could not divide the population according to asthma severity, we speculate that the patients with more severe asthma were referred more often to a specialist. Thus, some of the effects of meeting an asthma expert may be underestimated. Third, although a striking positive affect was demonstrated by specialist intervention, most pediatric asthma patients were not referred to a specialist. The fact that only a minority of asthma patients were included in the study might bias the findings. Again, the fact that the more severe patients were likely those who were referred, strengthens our observation. Another strength of the study is that in Israel, all children have health insurance. As such, there is easy access to medical treatment, emergency departments and to specialists, independent of socioeconomic status or geographic location. This enables an accurate exploration of asthma control in a large, heterogeneous pediatric population, without demographic or socioeconomic bias.

In conclusion, we demonstrated, a significant positive outcome of a single consultation with an asthma specialist, in a large cohort of children with asthma. This affected all elements of disease control. Referring pediatric asthma patients to an asthma specialist should be one of the goals of an asthma management plan.

\section{Abbreviations}

EMR, Electronic medical records; MHS, Maccabi Health Services; PCP, Primary care provider.

\section{Ethical Approval}

This study was approved by the MHS Institutional Review Board.

We confirm that the data accessed complies with relevant data protection and privacy regulations.

\section{Consent for Publication and Data Availability}

All manuscript data, tables and figures can be published. Data supporting our results will be shared upon request. 


\section{Author Contributions}

All authors made significant contributions to the conception and study design, drafted the manuscript, agreed on the journal to which the article was submitted; reviewed and agreed on all versions of the article before submission and agreed to take responsibility and to be accountable for the contents of the article.

\section{Funding}

This work was funded by Marom, a research program for physicians and residents in Maccabi Healthcare Services, Tel Aviv, Israel.

\section{Disclosure}

The authors declare no conflicts of interest.

\section{References}

1. Moorman JE, Akinbami LJ, Bailey CM, et al. National surveillance of asthma: United States, 2001-2010. Vital Health Stat. 2012;35:1-58.

2. Rehman N, Morais-Almeida M, Wu AC. Asthma across childhood: improving adherence to asthma management from early childhood to adolescence. J Allergy Clin Immunol Pract. 2020;8(6):1802-1807.e1. doi:10.1016/j.jaip.2020.02.011

3. Kenyon CC, Strane D, Floyd GC, et al. An asthma population health improvement initiative for children with frequent hospitalizations. Pediatrics. 2020;146(5):e20193108. doi:10.1542/ peds.2019-3108

4. Nurmagambetov T, Khavjou O, Murphy L, Orenstein D. State-level medical and absenteeism cost of asthma in the United States. $J$ Asthma. 2017;54(4):357-370. doi:10.1080/02770903.2016.1218 013

5. Sullivan PW, Slejko JF, Ghushchyan VH, et al. The relationship between asthma, asthma control and economic outcomes in the United States. J Asthma. 2014;51(7):769-778. doi:10.3109/027709 03.2014.906607
6. Cicutto L, Murphy S, Coutts D, et al. Breaking the access barrier: evaluating an asthma center's efforts to provide education to children with asthma in schools. Chest. 2005;128(4):1928-1935. doi:10.1378/ chest.128.4.1928

7. Janson SL, McGrath KW, Covington JK, Cheng S-C, Boushey HA. Individualized asthma self-management improves medication adherence and markers of asthma control. J Allergy Clin Immunol. 2009;123(4):840-846. doi:10.1016/j.jaci.2009.01.053

8. National Asthma Education and Prevention Program. Expert Panel Report 3 (EPR-3): guidelines for the diagnosis and management of asthma-summary report 2007. J Allergy Clin Immunol. 2007;120 (5Suppl):S94-138. doi:10.1016/j.jaci.2007.09.043

9. Agnihotri NT, Pade KH, Vangala S, Thompson LR, Wang VJ, Okelo SO. Predictors of prior asthma specialist care among pediatric patients seen in the emergency department for asthma. J Asthma. 2019;56(8):816-822. doi:10.1080/02770903.2018.1493600

10. Filler G, Kovesi T, Bourdon E, et al. Does specialist physician supply affect pediatric asthma health outcomes? BMC Health Serv Res. 2018;18(1):247. doi:10.1186/s12913-018-3084-z

11. Price D, Bjermer L, Bergin DA, Martinez R. Asthma referrals: a key component of asthma management that needs to be addressed. J Asthma Allergy. 2017;10:209-223. doi:10.2147/JAA.S134300

12. Hoch HE, Houin PR, Stillwell PC. Asthma in children: a brief review for primary care providers. Pediatr Ann. 2019;48(3):e103-e109. doi:10.3928/19382359-20190219-01

13. Slejko JF, Ghushchyan VH, Sucher B, et al. Asthma control in the United States, 2008-2010: indicators of poor asthma control. J Allergy Clin Immunol. 2014;133(6):1579-1587. doi:10.1016/j.jaci.2013.10.028

14. Abdoul C, Cros P, Coutier L, et al. Parents' views on artificial intelligence for the daily management of childhood asthma: a survey. J Allergy Clin Immunol Pract. 2021;9(4):1728-1730.e3. doi:10.1016/j.jaip.2020.11.048

15. Romano-Zelekha O, Graif Y, Garty B-Z, Livne I, Green MS, Shohat T. Trends in the prevalence of asthma symptoms and allergic diseases in Israeli adolescents: results from a national survey 2003 and comparison with 1997. J Asthma. 2007;44(5):365-369. doi:10.1080/02770900701363983

16. Grunwell JR, Gillespie S, Morris CR, Fitzpatrick AM. Latent class analysis of school-age children at risk for asthma exacerbation. $J$ Allergy Clin Immunol Pract. 2020;8(7):2275-2284.e2. doi:10.1016/j.jaip.2020.03.005

\section{Publish your work in this journal}

The Journal of Asthma and Allergy is an international, peer-reviewed open-access journal publishing original research, reports, editorials and commentaries on the following topics: Asthma; Pulmonary physiology; Asthma related clinical health; Clinical immunology and the immunological basis of disease; Pharmacological interventions and new therapies. The manuscript management system is completely online and includes a very quick and fair peer-review system, which is all easy to use. Visit http://www.dovepress.com/testimonials.php to read real quotes from published authors. 